\title{
Atropine-selective Membrane Electrodes and Relative Selectivity Concept
}

\author{
Mohsen M. ZAREH \\ Department of Chemistry, Faculty of Science, Zagazig University, Zagazig 44519, Egypt
}

\begin{abstract}
TFPB was introduced as a charged ionophore for atropine selective electrodes. Typical Nernstian responses were found $(57.78,58.95$ and $58.41 \mathrm{mV} /$ decade) for PVC-membrane electrodes incorporating NPOE, DOS, and DDP as plasticizers. They exhibited practical linear ranges of $9.1 \times 10^{-3}-10^{-6}, 9.1 \times 10^{-3}-10^{-6}$ and $9.1 \times 10^{-3}-10^{-7} \mathrm{M}$, respectively. It works in the sub-micro scale of atropine concentrations. The optimum $\mathrm{pH}$-range was $3.18-8.97$. The selectivity coefficient values were estimated for different organic and inorganic cations. They were interpreted by using the "Relative Selectivity Concept", which was introduced for the first time. The new concept was applied for comparing the selectivity properties of previously reported electrodes. The effect of the presence of ephedrine, caffeine, glucose, $\mathrm{Na}^{+}, \mathrm{Ca}^{2+}$, and $\mathrm{Mg}^{2+}$ on the calibration graphs of the electrodes was studied.
\end{abstract}

(Received May 23, 2007; Accepted September 25, 2007; Published July 10, 2008)

\section{Introduction}

Atropine sulfate $\left[\mathrm{C}_{17} \mathrm{H}_{23}\left(\mathrm{NO}_{3}\right)_{2} \cdot \mathrm{H}_{2} \mathrm{SO}_{4} \cdot \mathrm{H}_{2} \mathrm{O}\right.$ (694.83) $]$ is benzeneacetic, $\alpha$-(hydroxymethyl)-, $\quad 8$-methyl-8-azabicyclo[3.2.1] oct-3-yl ester, endo-( \pm )-sulfate (2:1) (salt) monohydrate. ${ }^{1}$ It is a tertiary amine, which can be obtained from plants of the solanaceous family, or prepared by synthesis. ${ }^{2}$ It is an antimuscarinic alkaloid with both central and peripheral anticholinergic effects. Atropine is employed topically as a mydriatic and cyclopleggic in ophthalmology.

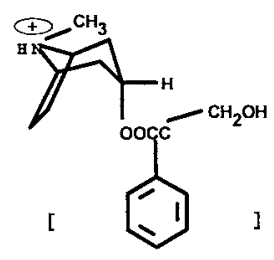

Atropinium ion $\left(\mathrm{ATH}^{+}\right)$

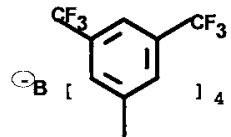

Tetrakis[3,5-bis(trifloromethyl)-

phenyl] borate (TFPB')
Several ion-selective electrodes sensitive to atropine ion were described in the literature. Some of them were based on the tetraphenylborate (TPB) salts..$^{3-7}$ Some other electrodes were based on different atropine-ionophores, like calix[6]arene, ${ }^{8}$ valinomycin, ${ }^{9}$ or charged ionophores, like $o$-phenylenediamine copolymer, ${ }^{10}$ atropine-picrolinate and atropinium 5nitrobarbiturate liquid membranes, ${ }^{11}$ or atropine-reineckate. ${ }^{12}$

All of the aforementioned electrodes were applied for atropine determination. However, none of the previous work had the ability to analyze atropine in the microscale range. Here, selective electrodes for atropine were prepared by immobilizing the most lipophilic borate salts, TFPB, into PVC-membrane for the first time. Superior to other borate salts, TFPB showed a

E-mail: mohsenzareh@hotmail.com response to atropine at submicroscale concentration levels. Accordingly, it is of importance to explain the properties of this electrode. The drug-sensor allows assessments of pharmaceutical formulations down to $10^{-7} \mathrm{M}$ concentration without the use of large volumes of solvents, e.g. trimethylsilyl derivatives, ${ }^{13}$ or toxic mercury-compounds in AAS, ${ }^{14}$ and is not highly expensive such as LC-MS. ${ }^{15}$ The most important issue is the introducing of the "Relative Selectivity Coefficient" concept. By applying this concept, the comparison between electrode selectivity becomes more specific and accurate.

\section{Theoretical}

Since the 1970's, many electrodes were predicted for the same cation or anion. They may have different plasticizers, ${ }^{16}$ ionophores ${ }^{17}$ or both. ${ }^{18}$ To decide which is practically preferred, a comparison of the performance characteristics should be introduced. One of the major decisions is that concerning the electrode selectivity. Many workers aimed to improve, ${ }^{19}$ and calculate $^{20-24}$ the selectivity coefficient of ISE. Some compared between methods of determination of the selectivity coefficient of ion-selective electrodes. ${ }^{25,26}$ Others studied the parameters that affect the selectivity coefficient values. ${ }^{27,28}$ Siswanta et al..$^{29}$ put a computer program for an evaluation and graphical representation of the selectivity coefficient.

Actually, nobody applied a mathematical rule for comparing the selectivity coefficient values. It depends on experience and a personal evaluation. Consequently, there must be a mathematical method to compare the electrode selectivity. A new assumption is introduced here, for the first time, which is called the "Relative Selectivity Concept".

The theory of the Relative Selectivity Concept is based on calculating the a new parameter " $\left(K_{\text {rel }}\right)_{x: y}$ ", the Relative Selectivity Coefficient (RSC) values for the electrode (X) under study relative to any other electrode (Y) to be compared with. Mathematically, the relative selectivity coefficient is obtained by 
Table 1 Selectivity coefficient values for the ATRH $^{+}$-electrodes I, II, and III based on TFPB using NPOE, DOS or DDP plasticizers at $10^{-2} \mathrm{M}$ interferent concentrations

\begin{tabular}{lccc}
\hline \multirow{2}{*}{ Interferent } & \multicolumn{3}{c}{$\log K_{\mathrm{Jz}, \mathrm{ATRH}}^{\mathrm{pot}}$} \\
\cline { 2 - 4 } & $\mathrm{I}$ & $\mathrm{II}$ & $\mathrm{III}$ \\
\hline $\mathrm{K}^{+}$ & -3.5 & -2.5 & -2.6 \\
$\mathrm{Li}^{+}$ & -4.2 & -3.8 & -4.0 \\
$\mathrm{Na}^{+}$ & -4.0 & -3.3 & -3.3 \\
$\mathrm{NH}_{4}{ }^{+}$ & -3.7 & -2.9 & -3.0 \\
$\mathrm{Mg}^{2+}$ & -5.2 & -5.4 & -5.5 \\
$\mathrm{Ca}^{2+}$ & -5.2 & -5.1 & -5.2 \\
$\mathrm{Ba}^{2+}$ & -5.1 & -4.8 & -4.9 \\
$\mathrm{Glutamic}_{\text {Arginin }}$ & -4.2 & -3.2 & -3.3 \\
Argid & -4.5 & -4.5 & -4.5 \\
$\mathrm{Glycine}_{\text {Ephedrine }}$ & -2.6 & -2.6 & -2.6 \\
Diphenhydramine & -0.96 & 0.31 & 0.34 \\
Caffeine & 1.5 & 2.1 & 2.2 \\
Quinine & -4.6 & -4.6 & -4.8 \\
Pilocarpine & 1.3 & 1.6 & 1.6 \\
\hline
\end{tabular}

dividing the selectivity coefficient value for an electrode $(\mathrm{X})$ by the selectivity coefficient of another electrode (Y) selective to the same ion, which is measured under the same experimental condition. The relative selectivity concept can be applied to any pair of electrodes that are selective to the same ion. $\mathrm{X}$ and $\mathrm{Y}$, which are labels for the compared electrodes, may be Roman (I, II, III ...) or Arabic numbers $(1,2,3, \ldots)$.

When considering three electrodes (I, II and III) selective to a certain ion (here it is atropinium ion), the following rules will help to calculate the relative selectivity coefficient:

1. The selectivity coefficient values of electrode $I\left(K_{\mathrm{i}, \mathrm{j}}^{\text {pot }}\right)_{\mathrm{I}}$ is calculated either by the SSM or the $\mathrm{FSM}^{21}$ for different interferents (Table 1). Under the same conditions, the selectivity coefficient values of electrode II, $\left(K_{\mathrm{i}, \mathrm{j}}^{\mathrm{pot}}\right)_{\mathrm{II}}$, is calculated for the same interferents. The same work is done for electrode III to calculate $\left(K_{\mathrm{i}, \mathrm{j}}^{\mathrm{pot}}\right)_{\text {IIII }}$.

2. The value of the RSC of electrode I toward electrodes II and III are represented by the following equations:

$$
\begin{aligned}
& \left(K_{\text {rel }}\right)_{\mathrm{IIII}-\mathrm{n}}=\left(K_{\mathrm{i}, \mathrm{j}}^{\mathrm{pot}}\right)_{\mathrm{I}} /\left(K_{\mathrm{i}, \mathrm{j}}^{\mathrm{pot}}\right)_{\mathrm{II}}, \\
& \left(K_{\mathrm{rel}}\right)_{\mathrm{I}: \mathrm{III}-\mathrm{n}}=\left(K_{\mathrm{i}, \mathrm{j}}^{\mathrm{pot}}\right)_{\mathrm{I}} /\left(K_{\mathrm{i}, \mathrm{j}}^{\mathrm{pot}}\right)_{\mathrm{III}} .
\end{aligned}
$$

Here, $\left(K_{\mathrm{i}, \mathrm{j}}^{\mathrm{pot}}\right)_{\mathrm{I}}$ and $\left(K_{\mathrm{i}, \mathrm{j}}^{\mathrm{pot}}\right)_{\mathrm{II}}$ are the selectivity coefficients for electrodes I and II toward an interferent cation $(n) .\left(K_{\text {rel }}\right)_{\text {I:II }}$ and $\left(K_{\text {rel }}\right)_{\text {I:III }}$ are the RSC values for electrode I towards electrodes II and III, respectively. Table 2, gives the calculated values for an atropine electrode.

3. By the same way, the RSC for electrode II can be calculated toward electrodes I and III:

$$
\begin{aligned}
& \left(K_{\text {rel }}\right)_{I I I-\mathrm{I}}=\left(K_{\mathrm{i}, \mathrm{j}}^{\mathrm{pot}}\right)_{\mathrm{II}} /\left(K_{\mathrm{i}, \mathrm{j}}^{\mathrm{pot}}\right)_{\mathrm{I}}, \\
& \left(K_{\text {rel }}\right)_{\mathrm{II}: I I I-\mathrm{n}}=\left(K_{\mathrm{i}, \mathrm{j}}^{\mathrm{pot}}\right)_{\mathrm{II}} /\left(K_{\mathrm{i}, \mathrm{j}}^{\mathrm{pot}}\right)_{\mathrm{III}} .
\end{aligned}
$$

4. Similarly, the RSC for electrode III can be calculated toward electrodes I and II:

$$
\begin{aligned}
& \left(K_{\text {rel }}\right)_{\text {III:I-n }}=\left(K_{\mathrm{i}, \mathrm{j}}^{\mathrm{pot}}\right)_{\mathrm{III}} /\left(K_{\mathrm{i}, \mathrm{j}}^{\mathrm{pot}}\right)_{\mathrm{I}}, \\
& \left(K_{\mathrm{rel}}\right)_{\mathrm{III}: I I-\mathrm{n}}=\left(K_{\mathrm{i}, \mathrm{j}}^{\mathrm{pot}}\right)_{\mathrm{III}} /\left(K_{\mathrm{i}, \mathrm{j}}^{\mathrm{pot}}\right)_{\mathrm{II}} .
\end{aligned}
$$

5. The value of RSC (Eqs. (1) - (6)) indicates which electrode has the better selectivity properties toward the tested interferent. If $\left(K_{\mathrm{rel}}\right)_{\mathrm{I}: \mathrm{II}}<1$, this means that electrode I has better selectivity than electrode II. If $\left(K_{\text {rel }}\right)_{\mathrm{I}: I I}>1$, then electrode I has a worse selectivity than electrode II. If $\left(K_{\text {rel }}\right)_{\text {I:II }}$ $=1$, it is predicted that both electrodes have equal selectivity.

6. The RSC values for each electrode are calculated for all of the interferents under study (Table 2). Then, an average relative selectivity coefficient (ARSC) for electrode I relative to electrodes II $\left(K_{\mathrm{I}: \mathrm{II}}\right)_{\mathrm{av}}$ and III $\left(K_{\mathrm{I}: \mathrm{III}}\right)_{\mathrm{av}}$ can be calculated as below:

$$
\begin{aligned}
& \left(K_{\text {rel-IIII }}\right)_{\mathrm{av}}=\left[\Sigma_{1 \rightarrow \mathrm{n}}\left(K_{\text {rel }}\right)_{\mathrm{I}: \mathrm{II}-\mathrm{n}}\right] / n, \\
& \left(K_{\text {rel-IIIIII }}\right)_{\mathrm{av}}=\left[\Sigma_{1 \rightarrow \mathrm{n}}\left(K_{\text {rel }}\right)_{\mathrm{I}: \mathrm{III}-\mathrm{n}}\right] / n .
\end{aligned}
$$

Here, $n$ is the number of interferents under study.

Similar equations for calculating $\left(K_{\text {rel-IIII) }}\right)_{\text {av }},\left(K_{\text {rel-IIIIIII }}\right)_{\mathrm{av}},\left(K_{\text {rel-IIIIII }}\right)_{\mathrm{av}}$ and $\left(K_{\text {rel-III:II }}\right)_{\text {av }}$ are obeyed.

7. The total average relative selectivity coefficient (TARSC) for electrode I relative to electrodes II and III can be calculated as

$$
\left(K_{\text {rel-II }}\right)_{\text {total }}=\left[\left(K_{\text {rel-IIII }}\right)_{\mathrm{av}}+\left(K_{\text {rel-IIIIII }}\right)_{\mathrm{av}}\right] / 2 .
$$

Here, the dominator of Eq. (9) is the number of electrodes that electrode I is compared to.

Similarly, $\left(K_{\text {rel-II }}\right)_{\text {rel }}$ and $\left(K_{\text {rel-III }}\right)_{\text {rel }}$ are calculated as

$$
\begin{aligned}
& \left(K_{\text {rel-II }}\right)_{\text {total }}=\left[\left(K_{\text {rel-IIII }}\right)_{\mathrm{av}}+\left(K_{\text {rel-II:III }}\right)_{\mathrm{av}}\right] / 2, \\
& \left(K_{\text {rel-III }}\right)_{\text {total }}=\left[\left(K_{\text {rel-IIIII }}\right)_{\mathrm{av}}+\left(K_{\text {rel-III:II }}\right)_{\mathrm{av}}\right] / 2 .
\end{aligned}
$$

This can be generalized for a number $(m)$ of electrodes selective to the same ion. The relative selectivity of electrodes I, II, or III compared to the number $(m)$ of electrodes can be expressed as follows:

$$
\begin{aligned}
& \left(K_{\text {rel-I }}\right)_{\text {total }}=\left[\left(K_{\text {rel-1:III }}\right)_{\mathrm{av}}+\left(K_{\text {rel--IIIII }}\right)_{\mathrm{av}}+\left(K_{\text {rel-I:IV }}\right)_{\mathrm{av}}+\right. \\
& \left.\left(K_{\text {rel-I: }}\right)_{\text {av }}+\ldots . .+\left(K_{\text {rel-I:m }}\right)_{\text {av }}\right] / m \text {, } \\
& \left(K_{\text {rel-II }}\right)_{\text {total }}=\left[\left(K_{\text {rel-II:I }}\right)_{\mathrm{av}}+\left(K_{\text {rel-II:III }}\right)_{\text {av }}+\left(K_{\text {rel-IIIIV }}\right)_{\text {av }}+\right. \\
& \left.\left(K_{\text {rel-II:V }}\right)_{\text {av }}+\ldots . .+\left(K_{\text {rel-II:m }}\right)_{\text {av }}\right] / m \text {, } \\
& \left(K_{\text {rel-III }}\right)_{\text {total }}=\left[\left(K_{\text {rel-III:I }}\right)_{\mathrm{av}}+\left(K_{\text {rel-III:II }}\right)_{\mathrm{av}}+\left(K_{\text {rel-III:IV }}\right)_{\mathrm{av}}+\right. \\
& \left.\left(K_{\text {rel-III:V }}\right)_{\mathrm{av}}+\ldots .+\left(K_{\text {rel-III:m }}\right)_{\mathrm{av}}\right] / m \text {. }
\end{aligned}
$$

This can be expressed as a general equation (Zareh's-equation), where $\mathrm{X}$ (can be replaced by symbols I, II, III, ...) is the electrode under study; $(1,2,3, \ldots . m)$ are numbers those refer to electrodes to be compared with:

$$
\begin{aligned}
& \left(K_{\text {rel-X }}\right)_{\text {total }}=\left[\left(K_{\text {rel-X:1 } 1)_{\mathrm{av}}}+\left(K_{\text {rel-X:2 }}\right)_{\mathrm{av}}+\left(K_{\text {rel-X:3 }}\right)_{\mathrm{av}}+\right.\right.
\end{aligned}
$$

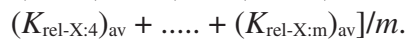

Here, $\mathrm{X}$ is the electrode under study; $(1,2,3,4, \ldots . m)$, refers to the number of electrodes to be compared with.

It can be predicted that the smaller is the $K$-value, the better are the selectivity properties of an electrode.

\section{Experimental}

All of the used reagents were of analytical grade. Chloride salts of inorganic cations were used. Deionized water was operated throughout the whole work for preparing different solutions and 
Table 2 Calculation of the relative selectivity coefficient values of I, II, and III atropine selective electrodes based on TFPB using NPOE, DOS or DDP plasticizers at $10^{-2} \mathrm{M}$ interferent concentrations

\begin{tabular}{|c|c|c|c|c|c|c|}
\hline \multirow{2}{*}{ Interferent } & \multicolumn{2}{|c|}{$\left(K_{\mathrm{rel}}\right)_{\mathrm{I}}$} & \multicolumn{2}{|c|}{$\left(K_{\text {rel }}\right)_{\text {II }}$} & \multicolumn{2}{|c|}{$\left(K_{\mathrm{rel}}\right)_{\mathrm{III}}$} \\
\hline & $\left(K_{\text {rel }}\right)_{\mathrm{IIII}}$ & $\left(K_{\text {rel }}\right)_{\mathrm{I}: \mathrm{III}}$ & $\left(K_{\mathrm{rel}}\right)_{\mathrm{III}}$ & $\left(K_{\text {rel }}\right)_{\text {II:III }}$ & $\left(K_{\text {rel }}\right)_{\text {III:I }}$ & $\left(K_{\text {rel }}\right)_{\text {III:II }}$ \\
\hline $\mathrm{K}^{+}$ & 0.10 & 0.12 & 9.99 & 1.25 & 7.94 & 0.79 \\
\hline $\mathrm{Li}^{+}$ & 0.39 & 0.63 & 2.51 & 1.58 & 1.58 & 0.63 \\
\hline $\mathrm{Na}^{+}$ & 0.19 & 0.19 & 5.01 & 1 & 5.01 & 1 \\
\hline $\mathrm{NH}_{4}^{+}$ & 0.15 & 0.19 & 6.30 & 1.25 & 5.01 & 0.79 \\
\hline $\mathrm{Mg}^{2+}$ & 1.58 & 1.99 & 0.63 & 1.25 & 0.50 & 0.79 \\
\hline $\mathrm{Ca}^{2+}$ & 0.79 & 1 & 1.25 & 1.25 & 1 & 0.79 \\
\hline $\mathrm{Ba}^{2+}$ & 0.50 & 0.63 & 1.99 & 1.25 & 1.58 & 0.79 \\
\hline Glutamic acid & 0.1 & 0.12 & 10 & 1.25 & 7.94 & 0.79 \\
\hline Arginin & 1 & 1 & 1 & 1 & 1 & 1 \\
\hline Glycine & 1 & 1 & 1 & 1 & 1 & 1 \\
\hline Ephedrine & 0.05 & 0.05 & 18.62 & 0.93 & 19.95 & 1.07 \\
\hline Diphenhydramine & 0.25 & 0.19 & 3.98 & 0.79 & 5.01 & 1.25 \\
\hline Caffeine & 1 & 1.58 & 1 & 1.58 & 0.63 & 0.63 \\
\hline Quinine & 0.50 & 0.50 & 1.99 & 1 & 1.99 & 1 \\
\hline Pilocarpine & 1.12 & 1.23 & 0.89 & 1.09 & 0.81 & 0.91 \\
\hline$\left(K_{\text {rel-X }}\right)_{\text {av XeI, II, or III }}$ & 0.58 & 0.69 & 4.41 & 1.16 & 4.06 & 0.88 \\
\hline$\left(K_{\text {rel-X }}\right)_{\text {total X=I, II, or III }}$ & \multicolumn{2}{|c|}{0.64} & \multicolumn{2}{|c|}{2.79} & \multicolumn{2}{|c|}{2.47} \\
\hline
\end{tabular}

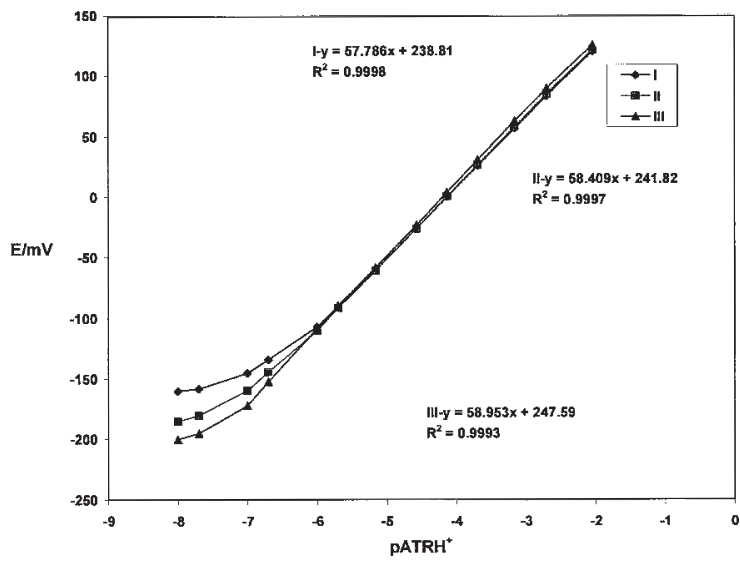

Fig. 1 Calibration graphs for different ATRH ${ }^{+}$-electrodes comprising membranes containing NPOE (I), DOS (II) and DDP (III) as plasticizers.

for rinsing the electrodes. Atropine sulfate was assayed according to the recommended pharmacopeia's method. ${ }^{1}$

The membranes were prepared using $1 \mathrm{wt} \%$ of K-TFPB, and NPOE, DOS, DDP, corresponding to electrode types-I, II or III. KTFPB was immobilized into $30-31 \mathrm{wt} \%$ of PVC and $55-60$ $\mathrm{wt} \%$ of any of the mentioned plasticizer. A total of $200 \mathrm{mg}$ was dissolved in $2 \mathrm{ml}$ of freshly distilled THF. The procedure for the electrode preparation was previously described.

Details for the emf measurement were published previously. ${ }^{8}$ The performance of the electrodes was examined by measuring the emf in primary ion solutions over a concentration range of $1 \times 10^{-8}$ to $1 \times 10^{-2} \mathrm{M}$. The selectivity coefficient, $K_{\mathrm{ATRH}}^{\mathrm{pot} \mathrm{J}^{I^{+}}}$, was calculated for inorganic cations, amino acids and amines (as their protonated forms). It was determined according to the separate solution method (SSM) using a $0.01 \mathrm{M}$ interferent solution as previously described. ${ }^{21}$

\section{Results and Discussion}

Membrane composition and electrode performance

The behavior of three electrodes (I, II, and III) can be correlated to the plasticizer structure. It is expected that the positive atropinium ion will prefer the high donation sites in TFPB. However, the presence of a plasticizer would introduce other sites for chelation. The presence of the ether plasticizer (NPOE) created an electrode (I) with Nernstain slope of 57.79 $\mathrm{mV} /$ decade, while the ester plasticizers (DDP and DOS) lead to electrodes (II and III) with slopes of 58.41 and $58.95 \mathrm{mV} /$ decade.

The selectivity coefficient indicates the extent of chelation of the primary ion into the membrane. The higher are the selectivity coefficient values, the more is the electrode membrane attacked by the interferent cations. Table 1 gives these values for all electrode types. The selectivity coefficient values for electrode-I were better than those for electrodes-II and -III. This is because the presence of the more polar NPOE leads to a better binding of the atropinium ion, which arises like lower selectivity coefficient values. This fact entails that the atropinium ion is more strongly bonded in membrane I than in membranes II and III.

After studying the calibration graph, it was found that the linear ranges of such electrodes were $10^{-6}-9.1 \times 10^{-3}, 10^{-6}-9.1$ $\times 10^{-3}$, and $10^{-7}-9.1 \times 10^{-3} \mathrm{M}$ for I, II, and III electrodes, respectively. Figure 1 shows the corresponding calibration graphs. This displays that the electrodes have practical linear ranges. Electrode I shows the shortest linear range. The detection limits of the three electrode types were estimated according to the IUPAC definition. ${ }^{21}$ Figure 1 shows that the electrode type-III had the best value, $6.3 \times 10^{-8} \mathrm{M}$.

The dynamic response was examined by recording the potential readings of each of the electrodes every $12 \mathrm{~s}$. A timepotential plot is shown in Fig. 2 for electrodes I, II and III. Ten different concentrations $\left(1 \times 10^{-7}, 1 \times 10^{-6}, 2 \times 10^{-6}, 6.92 \times 10^{-6}\right.$, $2.69 \times 10^{-5}, 7.4 \times 10^{-5}, 2.04 \times 10^{-4}, 6.9 \times 10^{-4}, 1.99 \times 10^{-3}$, and $9.14 \times 10^{-3} \mathrm{M}$ ) were tested. The response time was calculated according to the IUPAC-definition. For a $10^{-6} \mathrm{M}$ atropine solution the response times were 1,3.2 and $1.4 \mathrm{~min}$ for the three 


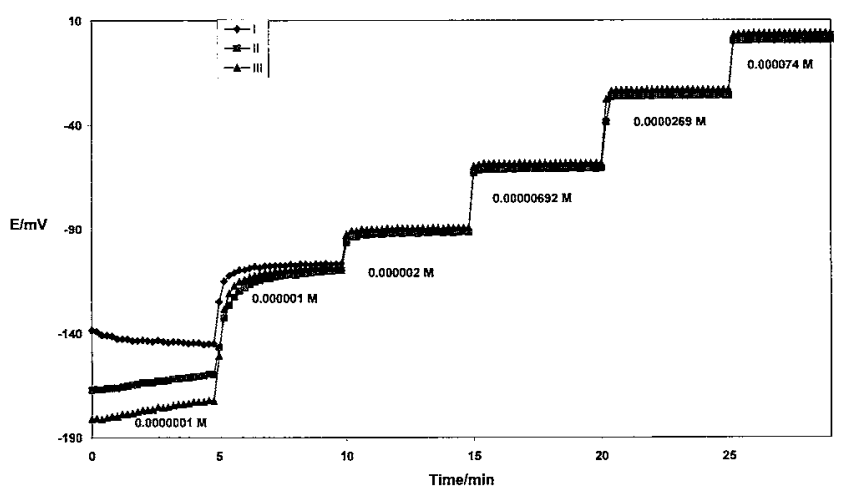

Fig. 2 Dynamic response of an atropine electrode based on TFPB with membranes containing NPOE (I), DOS (II), and DDP (III) plasticizers at concentrations between $1 \times 10^{-7}$ and $7.4 \times 10^{-5} \mathrm{M}$.

electrode types I, II, and III, respectively. It is noted that the steady state potential was reached after $24 \mathrm{~s}$ for $1.99 \times 10^{-6} \mathrm{M}$ $\mathrm{ATRH}^{+}$when any of the electrodes were used. Nevertheless, for higher concentrations, the electrodes attained steady state potentials after $12 \mathrm{~s}$. This reveals the fast electrode response as well as the steady potential readings.

The reproducibility of the electrodes was tested for the set of three electrodes prepared under the same conditions. The measurements were carried out five times over a period of three weeks. The average potential drift for the examined electrodes did not exceed $\pm 2.35 \mathrm{mV} /$ day for atropine concentrations of $10^{-6}-10^{-2} \mathrm{M}$ for all electrode types. This shows the stability of the electrode potential for the same concentration. When $10^{-7} \mathrm{M}$ ATR-solution was measured, the potential drift was higher (3.8, 7.8 , and $7.3 \mathrm{mV} /$ day for electrodes I, II, and III, respectively).

\section{pH-effect}

The pH-effect was studied for the I, II and III electrodes, which contained different plasticizers (NPOE, DOS and DDP). The plateau of the $\mathrm{pH}$-changes at different $\mathrm{ATRH}^{+}$ concentrations $\left(10^{-4}, 10^{-3}\right.$ and $\left.10^{-2} \mathrm{M}\right)$ were given. Their corresponding plateau $\mathrm{pH}$-ranges were 3.18 - 8.52, 3.97 - 7.99 and 2.9 - 8.9. Figure 3 shows the potential changes along with the $\mathrm{pH}$ variations for $10^{-3} \mathrm{M} \mathrm{ATH}^{+}$solutions. The formation of diprotonated species is the reason of the break in the curve at $\mathrm{pH}$ $<3.18,3.97$, or 2.9 for $10^{-4}, 10^{-3}$, or $10^{-2} \mathrm{M} \mathrm{ATRH}^{+}$, respectively. Nevertheless, in a basic medium, the break is due to the formation of a free atropine base. ${ }^{5}$

\section{Selectivity properties}

The selectivity coefficient, $K_{\mathrm{J}^{+*}, \mathrm{ATRH}^{+}}^{\text {pt }}$ (Table 1$)$, was calculated according to a separate solution method ${ }^{21}$ for three electrodes I, II, and III. Inorganic cations, like $\mathrm{K}^{+}, \mathrm{Li}^{+}, \mathrm{Na}^{+}, \mathrm{NH}_{4}{ }^{+}, \mathrm{Mg}^{2+}$, $\mathrm{Ca}^{2+}$, and $\mathrm{Ba}^{2+}$, were chosen for selectivity studies, since they are significant to biological fluids. The values of the selectivity coefficient of the tested monovalent cations $\left(\mathrm{Li}^{+}, \mathrm{K}^{+}, \mathrm{Na}^{+}\right.$, and $\mathrm{NH}_{4}{ }^{+}$) changes between -2.5 and -4.2 . $\mathrm{Li}^{+}$-ion exhibits the smallest selectivity coefficient value among the three electrodes. This is explained being because lithium ion has the least ionic radius $(0.68 \AA)$ among the tested mononvalent cations. This makes it loosely bonded to the borate-donation sites. The divalent cations possess good values of the selectivity coefficients $-4.8--5.5$. This is due to differences in the charge nature. The presence of a primary amine group is essential for the sensor response to atropine, and thus different compounds containing amino groups are of importance for these studies.

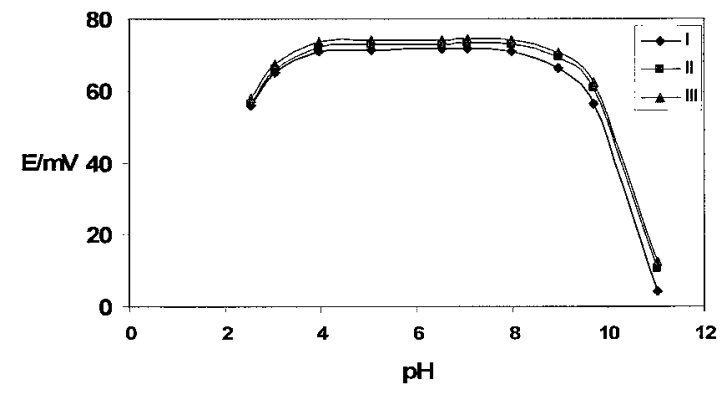

Fig. $3 \mathrm{pH}$ effect on potential of an atropine electrode based on TFPB with NPOE (I), DOS (II), and DDP (III) plasticizers when measuring $0.001 \mathrm{M}$ atropine concentration.

Among the tested amino acids with the $-\mathrm{NH}_{2}$ group, only arginine showed a $K_{\mathrm{J}^{+}, \mathrm{ATRH}}^{\mathrm{pot}}$ value that exhibited the best performance with all electrode types $(-4.5)$, but the other tested amines showed Msuitable values -2.6 - -4.2. Different categories of acyclic amine-based pharmaceutical compounds were chosen for selectivity studies (e.g., ephedrine and diphenhydramine). Other pharmaceuticals had an $\mathrm{N}$-atom in a cyclic structure (e.g., pilocarpine, quinine, and caffeine). It was found that quinine and diphenhydramine interfered with the proposed atropine determination for all three electrode types. Their $K_{\mathrm{J}^{+}}^{\mathrm{pot}}$ ATRH $^{+}$ranges were $1.3-1.6$ and $1.5-2.2$ toward the above-mentioned pharmaceutical compounds whatever was the used plasticizer. It was realized that the use of these electrodes can not be recommended in the presence of these compounds. Opposite of that, atropine electrodes showed good selectivity values toward caffeine. However, poor selectivity coefficient values towards ephedrine and pilocarpine were recorded. Therefore, the presence of these compounds affects atropine measurements. One of the important observations is that membrane type I had the best selectivity coefficient values. Very likely, this can be ascribed to the preferential interaction between the atropinium cation and the polar ether group in NPOE.

The selectivity of the studied electrodes was compared together by using the relative selectivity concept. Table 2, shows that electrode I is the best among other tested electrodes. This is shown by the smallest value of TARSC $\left(K_{\text {rel-I }}\right)_{\text {total }}=0.64$. Accordingly, the use of this electrode is recommended when many interferences are expected.

To confirm the relative selectivity assumption, the same calculations were applied for previously ${ }^{8}$ prepared atropine electrodes based on three phosphorated calix[6]arene derivatives as ionophores. Table 3 gives the calculated values for the relative selectivity coeffiecients for the different electrodes. The obtained results show that electrode type II had the best selectivity behavior $\left(\right.$ TARSC, $\left.\left(K_{\text {rel-II }}\right)_{\text {total }}=0.6\right)$. This agrees with results in previous work, which showed that the type II electrode had the best selectivity.

It is important to check the electrode behavior in an actual mixture. Accordingly, the performance of the three tested electrodes in presence of several selected inorganic cations $\left(\mathrm{Na}^{+}\right.$ $=9.1 \times 10^{-3}, \mathrm{Ca}^{2+}=8.3 \times 10^{-3}$ and $\left.\mathrm{Mg}^{2+}=7.7 \times 10^{-3} \mathrm{M}\right)$ in the same solution was studied. There were no changes found for the electrode-I calibration curve regardless the number of interferences. In contrast, changes of calibration curves for electrodes II and III were observed when $\mathrm{Na}^{+}, \mathrm{Ca}^{2+}$ and $\mathrm{Mg}^{2+}$ were added to atropine solutions. The lower limit of the linearity range increased by one concentration decade. 
Table 3 Calculation of the relative selectivity coefficient values of atropine selective electrodes based on phosphorated calix[6]arene derivatives $^{8}$

\begin{tabular}{|c|c|c|c|c|c|c|}
\hline \multirow{2}{*}{ Interferent } & \multicolumn{2}{|c|}{$\left(K_{\mathrm{rel}}\right)_{\mathrm{I}}$} & \multicolumn{2}{|c|}{$\left(K_{\mathrm{rel}}\right)_{\mathrm{II}}$} & \multicolumn{2}{|c|}{$\left(K_{\text {rel }}\right)_{\text {III }}$} \\
\hline & $\left(K_{\text {rel }}\right)_{\mathrm{I}: I I}$ & $\left(K_{\text {rel }}\right)_{\mathrm{I}: I I I}$ & $\left(K_{\mathrm{rel}}\right)_{\mathrm{II}: \mathrm{I}}$ & $\left(K_{\text {rel }}\right)_{\text {II:III }}$ & $\left(K_{\text {rel }}\right)_{\text {III:I }}$ & $\left(K_{\text {rel }}\right)_{\text {III:II }}$ \\
\hline $\mathrm{Na}^{+}$ & 2.14 & 0.50 & 0.47 & 0.23 & 2.01 & 4.3 \\
\hline $\mathrm{K}^{+}$ & 1.20 & 0.45 & 0.83 & 0.38 & 2.21 & 2.6 \\
\hline $\mathrm{Li}^{+}$ & 1.51 & 0.25 & 0.66 & 0.17 & 3.94 & 6.0 \\
\hline $\mathrm{NH}_{4}{ }^{+}$ & 1.46 & 0.41 & 0.68 & 0.28 & 2.44 & 3.6 \\
\hline $\mathrm{Ca}^{2+}$ & 3.14 & 0.63 & 0.32 & 0.20 & 1.58 & 5.0 \\
\hline $\mathrm{Mg}^{2+}$ & 0.62 & 0.03 & 1.61 & 0.05 & 31.77 & 19.7 \\
\hline $\mathrm{Ba}^{2+}$ & 1.64 & 0.26 & 0.61 & 0.16 & 3.84 & 6.3 \\
\hline Glycine & 0.94 & 0.03 & 1.06 & 0.03 & 31.21 & 29.5 \\
\hline Arginine & 1.50 & 0.26 & 0.67 & 0.17 & 3.87 & 5.8 \\
\hline Glutamic acid & 9.94 & 1.63 & 0.10 & 0.16 & 0.61 & 6.1 \\
\hline Ephedrine & 1.20 & 1.04 & 0.83 & 0.87 & 0.96 & 1.2 \\
\hline Pilocarpine & 1.46 & 1.06 & 0.69 & 0.73 & 0.94 & 1.4 \\
\hline Dopamine & 4.01 & 1.38 & 0.25 & 0.34 & 0.72 & 2.9 \\
\hline Quinine & 0.82 & 1.38 & 1.22 & 1.69 & 0.73 & 0.6 \\
\hline Diphenhydamine & 0.80 & 1.31 & 1.24 & 1.62 & 0.77 & 0.6 \\
\hline$\left(K_{\mathrm{rel}-\mathrm{X}}\right)_{\mathrm{av}, \mathrm{X}=\mathrm{I}, \mathrm{II}, \text { or III }}$ & 2.16 & 0.77 & 0.75 & 0.47 & 5.84 & 6.36 \\
\hline$\left(K_{\text {rel-X }}\right)_{\text {total, } \mathrm{X}=\mathrm{I}, \mathrm{II} \text {, or III }}$ & \multicolumn{2}{|c|}{1.47} & \multicolumn{2}{|c|}{0.61} & \multicolumn{2}{|c|}{6.10} \\
\hline
\end{tabular}

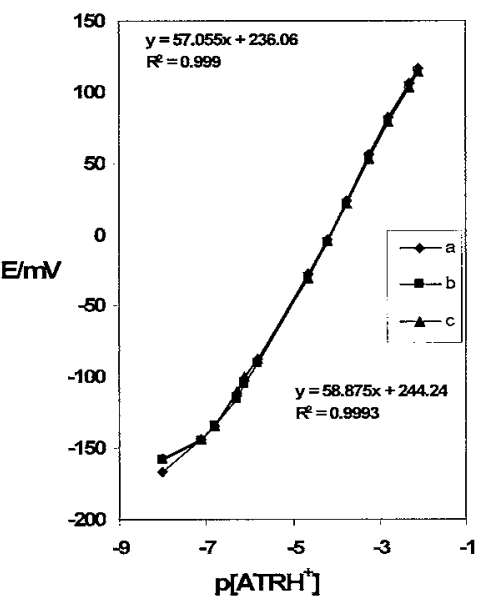

Fig. 4 Comparison of calibration graphs of $\mathrm{ATRH}^{+}$-electrode type III in ATRH $^{+}$alone (a), and in the presence of $9.1 \times 10^{-3} \mathrm{M}$ glucose (b) and in presence of $9.1 \times 10^{-3} \mathrm{M}$ glucose $+9.1 \times 10^{-3} \mathrm{M}$ caffeine (c).

Likewise, it is important to study the effect of the presence of some ingredients on the electrode behavior. Glucose, caffeine and ephedrine were chosen to perform this test. The presence of caffeine did not alter the linearity of the calibration graphs of any of the three electrodes (Fig. 4). This observation agrees with the selectivity coefficient values. In contrast, severe changes were found in presence of ephedrine. The lower linearity value of the calibration graph for electrode type-I changed from $2.0 \times 10^{-6}$ to $2.0 \times 10^{-4}$ or $6.9 \times 10^{-4} \mathrm{M}$ in the presence of either 0.000435 or $0.0083 \mathrm{M}$ ephedrine.

\section{Conclusion}

Due to the high lipophilicity of TFPB, it showed the highest selectivity and sensitivity towards atropinium ion, rather than other borates. Atropine can be assayed down to a $10^{-7} \mathrm{M}$ concentration. The highest lipophilic plasticizer DDP played a role in increasing the membrane sensitivity. A comparison of the selectivity of this electrode with others was conducted using the predicted "Relative Selectivity Concept".

The relative selectivity coefficient was introduced for a comparison of the selectivity of any number of electrodes those were responding to the same ion. Several parameters can be established. If you have electrodes (I, II, $\ldots, m$ ) to be compared regarding their selectivity towards interferents $(n)$. $\left(K_{\text {rel }}\right)_{\text {IIII }}$ is the relative selectivity coefficient (RSC) for electrode I relative to II for one interferent. $\left(K_{\text {rel-IIII }}\right)_{\text {av }}$ is the average relative selectivity coefficient (ARSC) of electrode I relative to electrode II; it is the average of all values of the studied interferents $(n)$. $\left(K_{\text {rel-I }}\right)_{\text {total }}$ is the total average relative selectivity coefficient (TARSC) of electrode I toward a number $(m)$ of electrodes; it equals the average of all (ARSC).

\section{References}

1. The United States Pharmacopeia, 2000, Asian Edition, January 1, US Pharmcopial Convention, Inc., MD, 178.

2. K. Parfitt, Martindale, The complete drug reference, 32nd ed., 1999, London, Pharmaceutical Press, 455.

3. N. Bibire, G. Tantaru, V. Dorneanu, M. Stan, and M. Apostu, Rev. Med. Chir. Soc. Med. Nat., 2003, 107, 218.

4. D. W. Wang, X. W. Li, and Y. Q. Liu, Fenxi Kexue Xuebao, 2002, 18, 237.

5. M. N. M. P. Alcada, J. L. F. C. Lima, and M. C. B. S. M. Montenegro, Anal. Sci., 1995, 11, 781 .

6. Y. Long, L. Lei, W. Li, D. He, L. Nei, and S. Yao, Analyst, 1999, 124, 1629.

7. S. S. Badawy, Y. M. Issa, and A. A. Mutair, J. Pharm. Biomed. Anal., 2005, 39, 117.

8. M. M. Zareh and E. Malinowska, J. AOAC Intl., 2007, 90, 147.

9. E. B. Nikol'skaya, B. N. Kormilitsyn, and L. I. Kugusheve, Zh. Anal. Khim., 2003, 58, 313

10. H. Peng, C. Liang, A. Zhou, Y. Zhang, Q. Xie, and S. Yao, Anal. Chim. Acta, 2000, 423, 221.

11. S. S. M. Hassan, M. A. Ahmed, and F. S. Tadros, Talanta, 1987, 34, 723.

12. S. S. M. Hassan and F. S. Tadros, Anal. Chem., 1984, 56, 
542.

13. S. S. D. Tanley, D. Mckemie, and W. Skinner, J. Anal. Toxicol., 2003, 27, 325.

14. M. A. Al-Reis and S. Khalil, J. Pharm. Biomed. Anal., 2001, 25, 3.

15. C. Kirchhokk, Y. Bitar, S. Ebel, and U. Holzbrobe, J. Chromatogr., 2004, 1046, 115.

16. M. M. Zareh, A. K. Gohnim, and M. Abd El-Aziz, Talanta, 2001, 54, 1049.

17. M. M. Zareh, R. Shohiab, and M. Abd-El-Fatah, Turk. J. Chem., 2006, 30, 307.

18. G. H. Zhang, T. Imato, Y. Asano, T. Sonoda, H. Kobayashi, and N. Ishibashi, Anal. Chem., 1990, 62, 1644.

19. A. S. Watts, V. G. Gavalas, A. Cammers, P. S. Andrada, M. Alajarin, and L. G. Bachas, Sens. Actuators, B, 2007, 121, 200.

20. K. Tohda, D. Dragoe, M. Shibata, and Y. Umezawa, Anal. Sci., 2001, 17, 733 .
21. G. Guilbault, R. Drust, M. Frant, H. Freiser, H. Hansen, T. Light, E. Pongor, G. Rechnitz, N. Rice, T. Rhom, W. Simon, and J. Thomas, Pure Appl. Chem., 1976, 48, 127.

22. S. Sodaye, G. Suresh, A. K. Pandey, and A. Goswami, J. Membr. Sci., 2007, 295, 108.

23. C. Maccà, Anal. Chim. Acta, 1996, 321, 1.

24. V. P. Y. Gadzekpo and G. D. Christian, Anal. Chim. Acta, 1984, 164, 279.

25. W. Zhang, A. Fakler, C. Demuth, and U. E. Spichiger, Anal. Chim. Acta, 1998, 375, 211.

26. E. Bakker, Anal. Chim. Acta, 1997, 350, 329.

27. V. V. Egorov, N. D. Borisenko, E. M. Rakhman'ko, Ya. F. Lushchik, and S. S. Kacharsky, Talanta, 1997, 44, 1735.

28. A. Hulanicki and Z. Augustowska, Anal. Chim. Acta, 1975, $78,261$.

29. D. Siswanta, H. Hisamoto, and K. Suzuki, TrAC Trends Anal. Chem., 1995, 14, 101. 